\title{
Evaluation of antinociceptive activity of nanoliposome-encapsulated and free-form diclofenac in rats and mice
}

This article was published in the following Dove Press journal:

International Journal of Nanomedicine

31 December 2014

Number of times this article has been viewed

\author{
Jun Zheng Goh' \\ Sook Nai Tang' \\ Hoe Siong Chiongl,2 \\ Yoke Keong Yong ${ }^{3}$ \\ Ahmad Zuraini' \\ Muhammad Nazrul Hakim ${ }^{1,4}$ \\ 'Department of Biomedical Sciences, \\ Universiti Putra Malaysia, Serdang, \\ Selangor, Malaysia; ${ }^{2}$ InQpharm Group, \\ Kuala Lumpur, Malaysia; ${ }^{3}$ Department \\ of Human Anatomy, ${ }^{4} \mathrm{Halal}$ Product \\ Research Institute, Universiti Putra \\ Malaysia, Serdang, Selangor, Malaysia
}

Correspondence: Muhammad Nazrul Hakim

Faculty of Medicine and Health Sciences, Universiti Putra Malaysia, 43400 UPM Serdang, Selangor, Malaysia Email nazrul.hakim@gmail.com

\begin{abstract}
Diclofenac is a nonsteroidal anti-inflammatory drug (NSAID) that exhibits anti-inflammatory, antinociceptive, and antipyretic activities. Liposomes have been shown to improve the therapeutic efficacy of encapsulated drugs. The present study was conducted to compare the antinociceptive properties between liposome-encapsulated and free-form diclofenac in vivo via different nociceptive assay models. Liposome-encapsulated diclofenac was prepared using the commercialized proliposome method. Antinociceptive effects of liposome-encapsulated and free-form diclofenac were evaluated using formalin test, acetic acid-induced abdominal writhing test, Randall-Selitto paw pressure test, and plantar test. The results of the writhing test showed a significant reduction of abdominal constriction in all treatment groups in a dosedependent manner. The $20 \mathrm{mg} / \mathrm{kg}$ liposome-encapsulated diclofenac demonstrated the highest antinociceptive effect at $78.97 \%$ compared with $55.89 \%$ in the free-form group at equivalent dosage. Both liposome-encapsulated and free-form diclofenac produced significant results in the late phase of formalin assay at a dose of $20 \mathrm{mg} / \mathrm{kg}$, with antinociception percentages of $78.84 \%$ and $60.71 \%$, respectively. Significant results of antinociception were also observed in both hyperalgesia assays. For Randall-Sellito assay, the highest antinociception effect of $71.38 \%$ was achieved with $20 \mathrm{mg} / \mathrm{kg}$ liposome-encapsulated diclofenac, while the lowest antinociceptive effect of $17.32 \%$ was recorded with $0 \mathrm{mg} / \mathrm{kg}$ liposome formulation, whereas in the plantar test, the highest antinociceptive effect was achieved at $56.7 \%$ with $20 \mathrm{mg} / \mathrm{kg}$ liposome-encapsulated diclofenac, and the lowest effect was shown with $0 \mathrm{mg} / \mathrm{kg}$ liposome formulation of $8.89 \%$. The present study suggests that liposome-encapsulated diclofenac exhibits higher antinociceptive efficacy in a dose-dependent manner in comparison with free-form diclofenac.
\end{abstract}

Keywords: diclofenac, liposome, nanoencapsulation, efficacy, antinociceptive

\section{Introduction}

The development of new drug formulations with improved safety and efficacy is always needed in order to achieve better therapeutic outcomes. However, invention of new drug formulations is costly and time-consuming, and hence various methods, including individualizing drug therapy, therapeutic drug monitoring, targeted drug delivery, and drug delivery at a slow and controlled rate, were developed to enhance the safety efficacy ratio of previously invented drugs. ${ }^{1}$

Application of nanotechnology to pharmacology has grown extensively in the past few decades, with the progressive development of biological delivery carriers for various active compounds. These delivery systems, which are comprised of various formulation approaches such as oily liquids, mixed micelles, self-emulsifying systems, solid lipid nanoparticles, liposomes, etc., are capable of overcoming anatomical and physiological barriers and transporting drugs effectively from the site of administration 
to the desired site of action. ${ }^{2,3}$ Among the various approaches, liposomal drug delivery systems have attracted considerable interest from researchers as liposomes have shown promising results in altering the bioavailability of entrapped therapeutic agents, thus improving the drug therapeutic index in terms of longevity, targetability, drug safety profiles, and therapeutic efficacy. ${ }^{4}$ In fact, several successful liposomal formulations are currently available commercially in the market and have been used in the treatment of clinical diseases. ${ }^{5,6}$

Liposomes, spherical unilamellar or multilamellar selfclosed structures with an aqueous core encapsulated by phospholipids, are effective pharmaceutical carriers because of several unique features, namely, their ability to encapsulate a broad range of hydrophilic and hydrophobic drugs, their biocompatibility, biodegradability, nontoxicity and nonimmunogenicity, and their ability to alter drug bioavailability, thus improving drug therapeutic efficacy. ${ }^{5,7}$ Previous studies have shown that liposomes serve as an effective tool in the delivery of a wide range of antiviral and antimicrobial agents, antifungal drugs, and chemotherapeutic agents and vaccines. ${ }^{8,9}$ Hence, utilization of this promising liposomal delivery system to enhance the antinociceptive properties of diclofenac is a clearly worthy attempt.

Diclofenac is a popular choice of nonsteroidal anti-inflammatory drug (NSAID) worldwide, and is commonly used as anti-inflammatory, analgesic, and antipyretic agents for the treatment of osteoarthritis, rheumatoid arthritis, ankylosing spondylitis, acute musculoskeletal injury, postoperative pain management, and sometimes in the relief of primary dysmenorrhea syndrome. ${ }^{10,11}$ Diclofenac reduces inflammation, swelling, and arthritic pain by direct inhibition of cyclooxygenase isozymes (COX-1 and COX-2) peripherally in injured tissues as well as in the central nervous system, which leads to the inhibition of prostaglandins production from arachidonic acid. ${ }^{12,13}$ In addition, diclofenac also exerts its action via the inhibition of the thromboxane-prostanoid receptor and lipoxygenase enzymes, and the activation of nitric oxide-cGMP antinociceptive pathway. ${ }^{14}$ In the present study, antinociceptive activity of liposome-encapsulated and free-form diclofenac was evaluated in vivo via different nociceptive assay models.

\section{Materials and method}

\section{Materials}

Diclofenac sodium salt and carrageenan, commercial grade, Type I were purchased from Sigma-Aldrich ${ }^{\circledR}$ (St Louis, MO, USA). Further, dimethyl sulfoxide (DMSO) 99.5\% from Sigma $^{\circledR}$ Life Science (USA), Pro-lipo ${ }^{\mathrm{TM}}$ Duo from Lucas
Meyer Cosmetics (Champlan, France), acetic acid 100\% from AnalaR ${ }^{\circledR}$ (WWR International Ltd. Poole, BH15 ITD, England, UK), and formaldehyde solution 37\%-38\% w/w stabilized with methanol from $\mathrm{HmbG}^{\circledR}$ Chemicals was purchased. Sartorius CPA224S laboratory balance and C-MAG HS 7 IKAMAG ${ }^{\circledR}$ magnetic stirrer were used for drug sample preparation. Ugo Basile dynamic plantar aesthesiometer and Ugo Basile 37370 plantar test (Hargreaves apparatus, Ugo Basile, Varese, Italy) were used for mechanical and thermal hyperalgesia test, respectively.

\section{Animals}

Healthy adult male Sprague Dawley rats (180-220 g) and male Balb/C mice (25-35 g) maintained in a 12-hour lightdark cycle at a controlled ambient temperature $\left(25^{\circ} \mathrm{C} \pm 2^{\circ} \mathrm{C}\right)$ with food and water ad libitum were used for the present study. The procedures in the present study were approved by the Animal Ethics Committee of Universiti Putra Malaysia (UPM/IACUC/AUP-R048/2013) and were performed in accordance with the Institutional Animal Ethics Committee (IAEC) guidelines.

\section{Liposome sample preparation}

Loaded liposomes with model drug, diclofenac, and blank liposomes were prepared in accordance with the manufacturer's (Lucas Meyer Cosmetics) instructions with some modifications. Preparation of liposome was carried out at room temperature $\left(25^{\circ} \mathrm{C} \pm 2^{\circ} \mathrm{C}\right)$ via a previously published method. ${ }^{15}$

Briefly, a fresh stock solution of diclofenac $(60 \mathrm{mg} / \mathrm{mL})$ was prepared daily by dissolving a predetermined quantity of diclofenac sodium powder in DMSO. Next, $1 \mathrm{~mL}$ of the stock diclofenac solution was added gradually to $5 \mathrm{~g}$ of Pro-lipo ${ }^{\mathrm{TM}}$ Duo in a beaker with moderate stirring $( \pm 100 \mathrm{rpm})$ for 1 hour. The mixture was then gradually hydrated with $9 \mathrm{~mL}$ of distilled water with moderate stirring for 10 hours. About $25 \mathrm{~mL}$ of distilled water was then added gradually with moderate stirring for 30 minutes to complete the process. Drug-loaded liposome prepared should be stored at $2^{\circ} \mathrm{C}-8^{\circ} \mathrm{C}$. Blank liposomes were prepared with a similar procedure by replacing the stock diclofenac solution with DMSO.

\section{Characterization}

The drug entrapment and size profiles of the freshly prepared liposomal samples (duplicate samples from three individual batches, $n=6$ ) were evaluated by the UV-visible spectrophotometric and photon correlation spectroscopy methods, respectively, as published elsewhere. ${ }^{16}$ Morphological observations 
of blank and nanoliposome-encapsulated diclofenac were then carried out by a Hitachi H7100 transmission electron microscope (JEOL, Ltd., Tokyo, Japan).

\section{Acetic acid-induced abdominal writhing test}

The acetic acid-induced abdominal writhing test was performed according to Parker et a ${ }^{17}$ and Zakaria et al. ${ }^{18}$ Male $\mathrm{Balb} / \mathrm{C}$ mice were placed in the transparent Perspex observation chamber for 20 minutes prior to the experiment to adapt to their surroundings. The mice were equally divided into eight groups $(n=6)$ and were orally administered different dosages of the treatment drug. 30 minutes after pretreatment each group was administered $0.6 \%(10 \mathrm{~mL} / \mathrm{kg})$ acetic acid via intraperitoneal injection. After a 5-minute lag following the acetic acid administration, the number of writhings (abdominal constriction followed by extension of the hind leg) was observed in a period of 30 minutes.

\section{Formalin test}

The formalin test procedure was similar to that described previously by Bukhari et $\mathrm{al}^{19}$ and Zakaria et $\mathrm{al}^{20}$ Sprague Dawley rats were placed in a Perspex observation chamber for 20 minutes prior to the experiment for the purpose of adaptation. Rats equally divided into eight groups $(n=6)$ were injected with $50 \mu \mathrm{L}$ of $2.5 \%$ formaldehyde via intraplantar route into the right hind paw 30 minutes after oral administration of the treatment drug. The pain effect shown by the amount of time the animal spent flinching or biting the injected paw was recorded at 0-5 minutes (early phase) and 15-30 minutes (late phase) after the injection of formalin.

\section{Randall-Sellito paw pressure test (mechanical hyperalgesia)}

This paw pressure test was conducted according to the method described by Woode et $\mathrm{al}^{21}$ and Zakaria et $\mathrm{a}^{22}$ The rats were placed on the Ugo Basile dynamic plantar aesthesiometer for 20 minutes prior to the experiment to enable them to adapt to their surroundings. Around 30 minutes after oral administration of the treatment drug, $50 \mu \mathrm{L}$ of
$1 \%$ carrageenan was injected into their right hind paws via intraplantar injection. A constant force of $20 \mathrm{~g} / \mathrm{s}$ was applied to the injected paw with cutoff time at 30 seconds, and the response time for nociceptive behavior (withdrawal of the injected paw) was recorded every hour for a continuous 5-hour interval.

\section{Plantar test (thermal hyperalgesia)}

The Hargreaves radiant heat method was carried out as demonstrated by Tao et al ${ }^{23}$ The rats were placed individually in clear plastic chambers of the Ugo Basile plantar test apparatus for 20 minutes prior to the experiment for the purpose of adaptation. 30 minutes after oral administration of the treatment drug, $50 \mu \mathrm{L}$ of $1 \%$ carrageenan was injected into their right hind paws via intraplantar injection. Heat stimulation was applied at IR 50 (infrared intensity 50) on the injected paw with a 30 -second cutoff time. Paw withdrawal latency time was measured every hour for a continuous 5-hour interval.

\section{Results}

\section{Characterization of liposomal samples}

The drug entrapment and size profiles of the liposomal samples used in the present work are shown in Table 1. Satisfactory drug entrapment and size profiles of $87 \%$ and $260 \mathrm{~nm}$, respectively, were obtained by the previously optimized proliposome preparation method. Liposomes were seen to be a population of spherical self-closed structures with concentric lamellae under a Hitachi H7100 transmission electron microscope (Figure 1).

\section{Acetic acid-induced abdominal writhing test}

The effect of different treatments on antinociceptive activity via the acetic acid-induced abdominal writhing test is shown in Figure 2. All treatment groups showed significant antinociceptive activities as compared with the control group. Statistical analysis also indicated that liposome-encapsulated diclofenac exhibited a significantly greater antinociceptive response when compared with its nonencapsulated form of $0.2,2$, and $20 \mathrm{mg} / \mathrm{kg}$ doses.

Table I Entrapment and size profiles of liposomal samples

\begin{tabular}{lllll}
\hline Liposomal sample & $\begin{array}{l}\text { Entrapment capacity } \\
\left(\mu \text { diclofenac/g Pro-lipo }^{\text {TM }}\right)\end{array}$ & Entrapment $(\%)$ & Particle size (nm) & Polydispersity index \\
\hline Diclofenac-loaded liposomes & $854.7 \pm 21.5$ & $87.4 \pm 1.3$ & $260.2 \pm 9$ & $0.27 \pm 0.013$ \\
Blank liposomes & N/A & N/A & $296.9 \pm 5.9$ & $0.32 \pm 0.015$ \\
\hline
\end{tabular}

Note: Values shown are mean \pm SEM ( $n=6 /$ group).

Abbreviations: N/A, not applicable; SEM, standard error of the mean. 

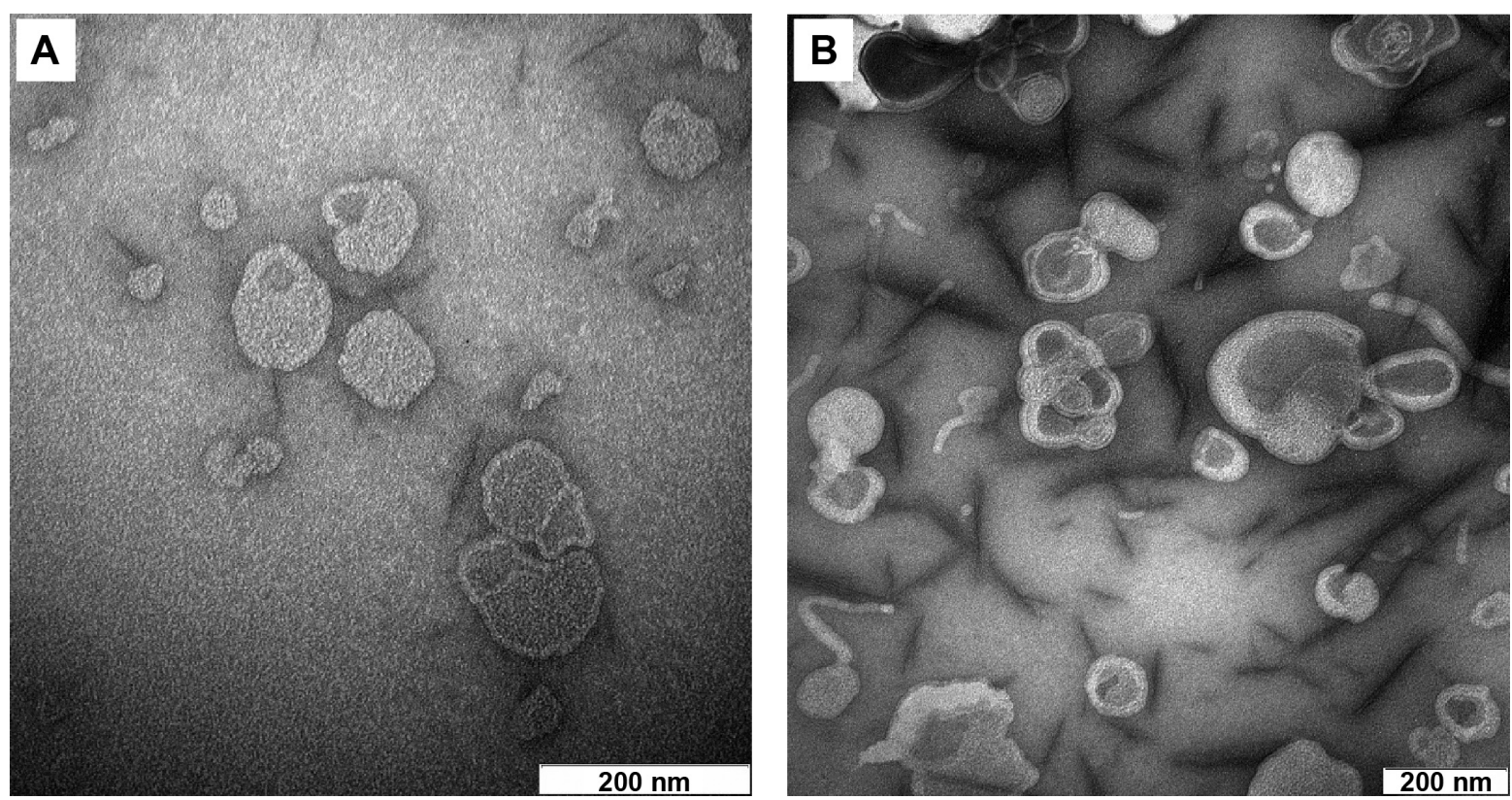

Figure I Transmission electron microscope image of (A) blank liposome and (B) diclofenac sodium-loaded liposome.

\section{Formalin test}

The antinociceptive activity, which was indicated by the reduction in the paw licking time of the animals, was observed in a dose-dependent manner in both early and late phases of the experiment (Figure 3). A significant increase in pain inhibition was observed in the late phase

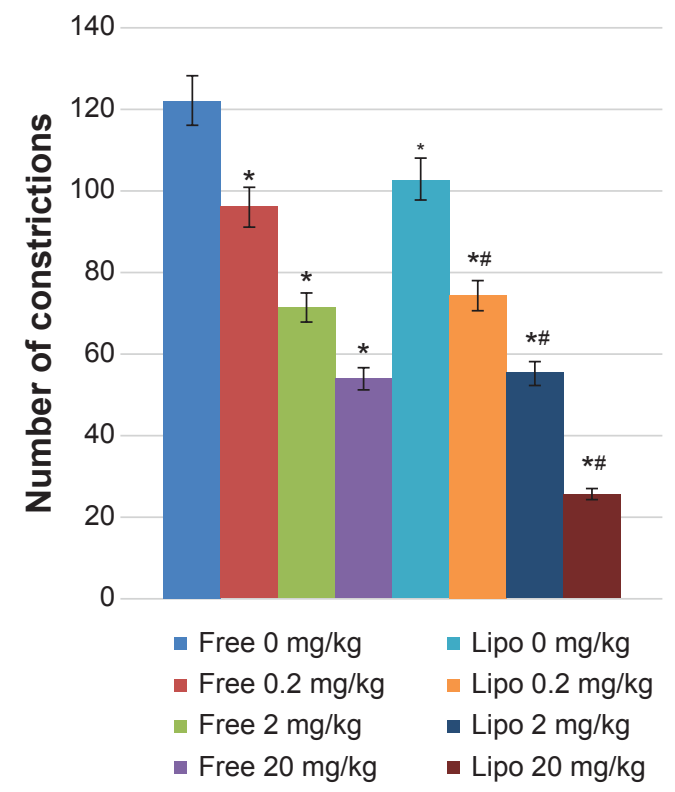

Figure 2 Effects of different treatments of liposome-encapsulated and free-form diclofenac on acetic acid-induced abdominal constriction in mice.

Notes: Values shown are mean \pm SEM ( $n=6 /$ group). *Significant difference $(P<0.05)$ when compared with control (diclofenac, $0 \mathrm{mg} / \mathrm{kg})$; \#Significant difference $(P<0.05)$ when compared with group of equivalent dosage of diclofenac.

Abbreviations: Lipo, liposome-encapsulated diclofenac; SEM, standard error of the mean. (inflammatory phase) for all groups compared with those of the early phase (neurogenic phase). Liposome-encapsulated diclofenac showed better inflammatory pain inhibition when compared with the respective nonencapsulated form of all equivalent dosages, with the highest pain inhibition achieved by $20 \mathrm{mg} / \mathrm{kg}$ liposome-encapsulated diclofenac at $78.84 \%$.

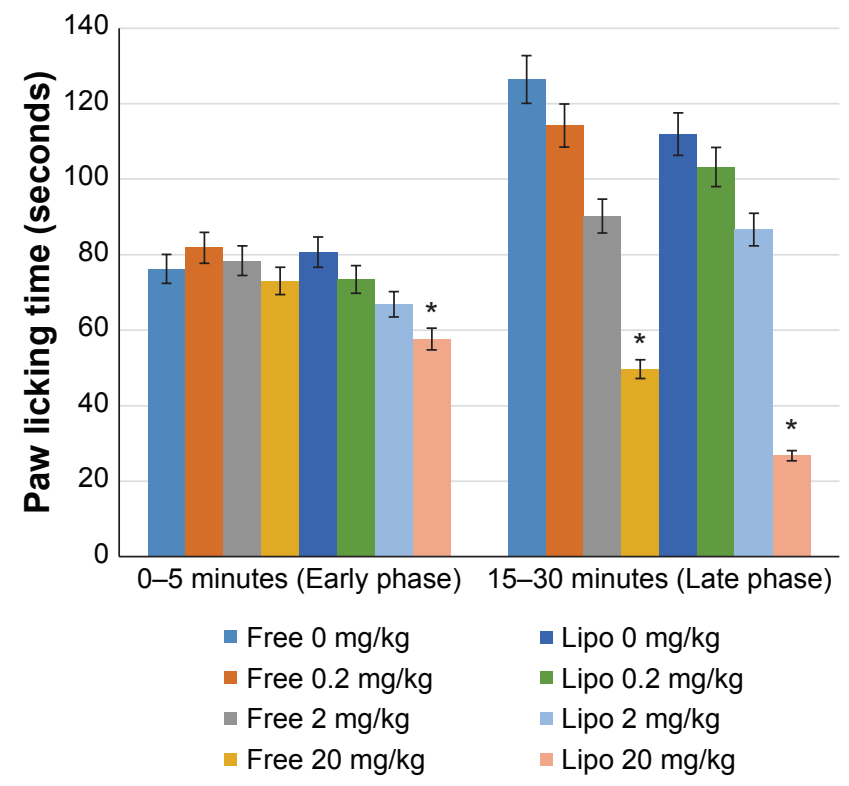

Figure 3 Effects of different treatments of liposome-encapsulated and free-form diclofenac on paw licking time in rats.

Notes: Values shown are mean \pm SEM ( $n=6 /$ group). *Significant difference $(P<0.05)$ when compared with control (diclofenac, $0 \mathrm{mg} / \mathrm{kg}$ ).

Abbreviations: Lipo, liposome-encapsulated diclofenac; SEM, standard error of the mean. 


\section{Randall-Sellito paw pressure test (mechanical hyperalgesia)}

Statistical analysis indicated that all treatment groups showed significantly greater tolerance of mechanical hyperalgesia compared with the control group (Figure 4). Liposomeencapsulated diclofenac exhibits a greater tolerance for carrageenan-induced mechanical hyperalgesia at various experimental time points compared with its nonencapsulated form at all equivalent dosages. The highest percentage of inhibition, at $109.4 \%$, was observed at the second hour after carrageenan injection in rats treated with $20 \mathrm{mg} / \mathrm{kg}$ liposomeencapsulated diclofenac.

\section{Plantar test (thermal hyperalgesia)}

The results of carrageenan-induced thermal hyperalgesia showed significant prolongation of paw withdrawal latencies at various experimental time points in all treatment groups when compared with the control group (Figure 5).

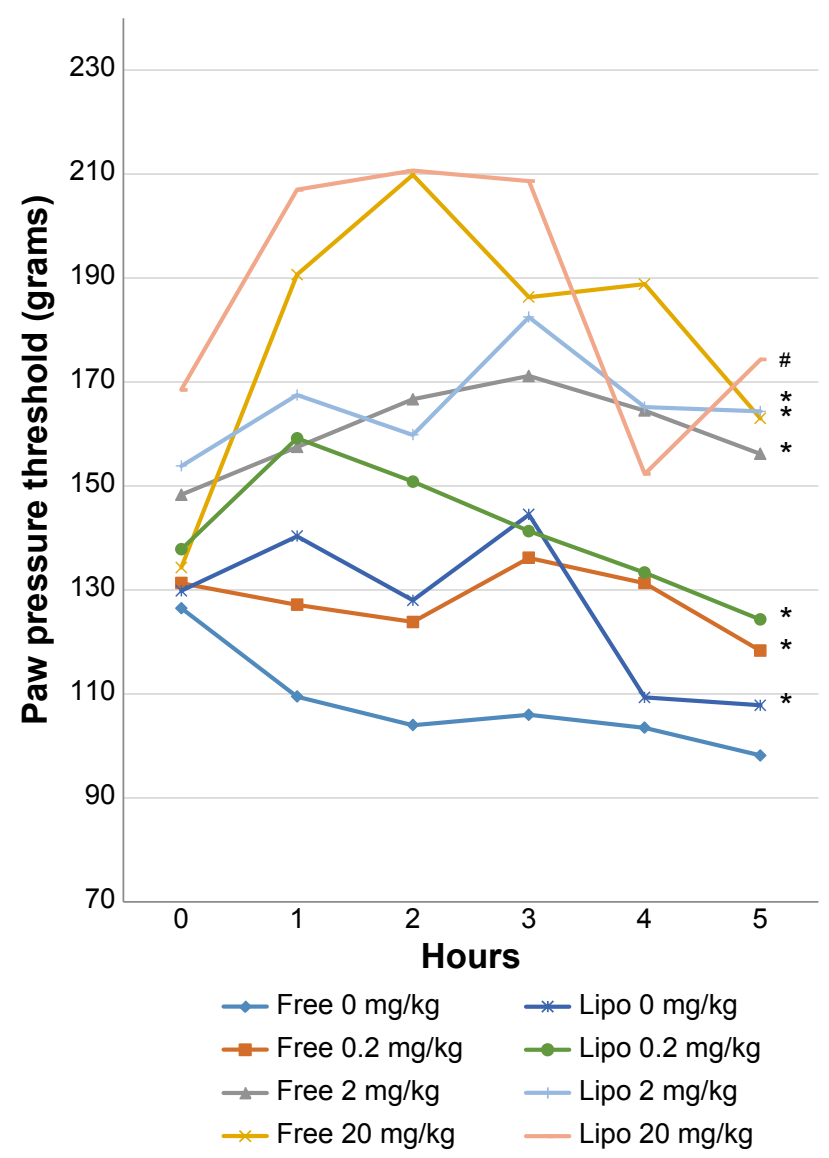

Figure 4 Effects of different treatments of liposome-encapsulated and free-form diclofenac on rats' paw pressure threshold at various experimental time points.

Notes: Values shown are mean \pm SEM ( $n=6 /$ group). *Significant difference $(P<0.05)$ when compared with control (diclofenac, $0 \mathrm{mg} / \mathrm{kg}$ ); \#Significant difference $(P<0.05)$ when compared with group of equivalent dosage of diclofenac.

Abbreviations: Lipo, liposome-encapsulated diclofenac; SEM, standard error of the mean.
Liposome-encapsulated diclofenac exhibited a greater tolerance of carrageenan-induced thermal hyperalgesia when compared with the nonencapsulated group at respective dosages. Statistical analysis also showed significant differences at the fourth and fifth hours when $20 \mathrm{mg} / \mathrm{kg}$ liposome-encapsulated diclofenac was compared with free-form diclofenac of equivalent dose.

\section{Discussion}

Pain and inflammation have been involved in various pathological conditions such as arthritis, vascular diseases, and cancer. ${ }^{24,25}$ Liposomal delivery systems, with their ability to improve a drug's therapeutic efficacy, are therefore of importance in achieving effective disease management. It is widely accepted that pain sensation can be evaluated by nociceptive tests (dolorimetry in animals) based on overt behavioral responses or nociceptive reflex responses directly triggered by a noxious stimulus. ${ }^{26}$ In the present study, we evaluated the antinociceptive effects between liposome-encapsulated and free-form diclofenac via several well-established nociception assays with different pain stimuli (thermal, mechanical, or chemical) and specificities.

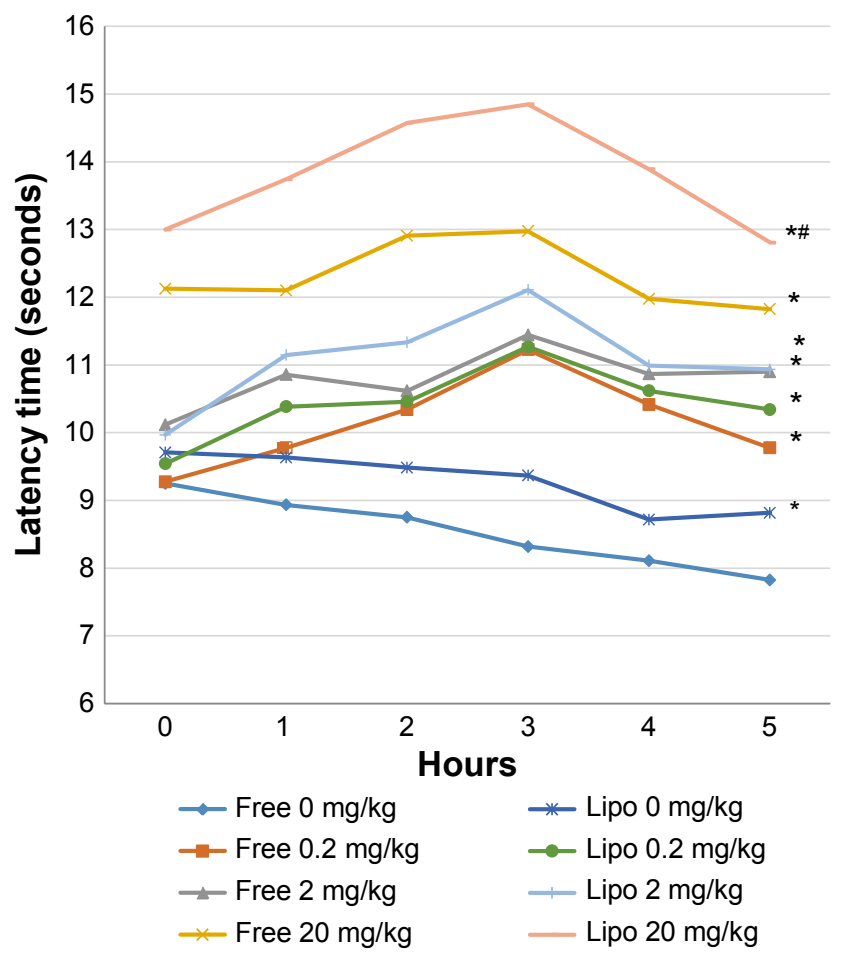

Figure 5 Effects of different treatments of liposome-encapsulated and free-form diclofenac on paw withdrawal latencies of rats at various experimental time points. Notes: Values shown are mean \pm SEM $(n=6 /$ group $)$ * Significant difference $(P<0.05)$ when compared with control (diclofenac, $0 \mathrm{mg} / \mathrm{kg}$ ); \#Significant difference $(P<0.05)$ when compared with group of equivalent dosage of diclofenac.

Abbreviations: Lipo, liposome-encapsulated diclofenac; SEM, standard error of the mean. 
Nanoencapsualtion of diclofenac via Pro-lipo ${ }^{\mathrm{TM}}$ Duo, a commercially available proliposome mixture consisting of water, alcohol, glycerin, and phosphatidylcholine, has been shown to be able to produce an optimum formulation with a high drug entrapment efficacy and enhanced drug therapeutic properties. Our previous study demonstrated that nanoencapsulation of diclofenac via Pro-lipo ${ }^{\text {TM }}$ Duo with a higher drug concentration, 10 hours' hydration time yields a small ( $<300 \mathrm{~nm}$ ), homogeneous (polydispersity index, 0.27 ), stable, and reproducible formulation that exerts improved anti-inflammatory effects when compared with free-form diclofenac of equivalent dosage. ${ }^{16}$

The acetic acid-induced writhing test is a sensitive screening assay that is commonly used to study both central and peripheral antinociceptive responses, ${ }^{27}$ whereas the formalininduced paw licking test is well established in the elucidation of a compound's mechanism of action at both the peripheral and central levels, where the early phase is characterized by neurogenic pain as a result of direct nociceptors stimulation in the paw and the late phase is characterized by inflammatory pain response due to the release of algogenic substances from damaged tissues. ${ }^{28}$ Data obtained from the present study revealed that both liposome-encapsulated and free-form diclofenac exhibited dose-dependent pain inhibitory activities that were characterized by a significant reduction in writhing effect. Further evaluation via the formalin test suggested that liposome-encapsulated diclofenac is more effective in suppressing inflammatory pain and that stronger peripheralmediated antinociceptive activity could be attained using the present liposomal formulations. Indeed, encapsulation with liposomes ${ }^{29}$ or other material $\mathrm{s}^{30-32}$ will significantly improve a drug's efficacy, and thus reduce its side effects by using lower doses. ${ }^{33}$

Similarly to other NSAIDs, the usage of diclofenac is often associated with gastric mucosal erosion, ulceration, hemorrhage, epigastric pain, and platelet dysfunction owing to the inhibition of prostaglandin synthesis by cyclooxygenase enzyme (COX). ${ }^{33}$ Conventionally prescribed diclofenac formulation has also been reported to be more commonly associated with hepatotoxicity, gastrointestinal toxicity, and renal toxicity, especially during prolonged administration. ${ }^{34-36}$

Inflammatory pain involved complex mechanisms that, in general, are defined as a combination of spontaneous pain and hyperalgesia. The hyperalgesic response or enhanced sensitivity to pain after an inflammatory stimulus is characterized by a peripheral sensitization of nociceptors and nociceptive neurons through alteration in nervous system plasticity to inflammatory mediators released. ${ }^{37,38}$ Recent works have demonstrated the potential benefits of liposomal formulations in reducing hyperalgesic responses to mechanical and thermal stimuli with frequently used carrageenan-induced inflammation models. Data on recent hyperalgesia tests showed significant elevation in an animal's nociceptive thresholds to both mechanical and thermal stimuli with increased tolerance toward hyperalgesic response in all treatment groups compared with the control group, and higher antinociceptive effects when treated with liposomeencapsulated diclofenac.

\section{Conclusion}

In conclusion, the present study revealed that enhanced antinociceptive effects can be achieved in vivo by liposomal drug formulation of diclofenac. Liposome-encapsulated diclofenac was shown to exhibit greater antinociceptive effects when compared with the nonencapsulated form of diclofenac in animal models. Improved drug delivery and efficacy can be attributed to the ability of liposomal drug delivery systems to enhance drug solubility and effective delivery of their encapsulated contents to the site of action.

\section{Acknowledgment}

Funding for this work was provided by the Fundamental Research Grant Scheme (Grant number 04-1007-277FR) from the Ministry of Higher Education, Malaysia.

\section{Disclosure}

The authors report no conflicts of interest in this work.

\section{References}

1. Tiwari G, Tiwari R, Sriwastawa B, et al. Drug delivery systems: an updated review. Int J Pharm Investig. 2012;2(1):2-11.

2. Gaudana R, Ananthula HK, Parenky A, Mitra AK. Ocular drug delivery. AAPS J. 2010;12(3):348-360.

3. Kalepu S, Manthina M, Padavala V. Oral lipid-based drug delivery systems: an overview. APSB. 2013;3(6):361-372.

4. Elbayoumi TA, Torchilin VP. Current trends in liposome research. Methods Mol Biol. 2010;605:1-27.

5. Fan Y, Zhang Q. Development of liposomal formulations: from concept to clinical investigations. AJPS. 2013;8(2):81-87.

6. Goyal P, Goyal K, Vijaya Kumar SG, Singh A, Katare OP, Mishra DN. Liposomal drug delivery systems: clinical applications. Acta Pharm. 2005;55:1-25.

7. Mufamadi MS, Pillay V, Choonara YE, et al. A review on composite liposomal technologies for specialized drug delivery. Drug Deliv. 2011;19:1626-1635.

8. Popovska O, Simonovska J, Boskovic R, Kavrakovski Z, Rafajlovska V. An overview: methods for preparation and characterization of liposomes as drug delivery systems. Int J Pharm Phytopharmacol Res. 2013;3(3):182-189.

9. Chang HI, Yeh MK. Clinical development of liposome-based drugs: formulation, characterization, and therapeutic efficacy. Int J Nanomed. 2012;7:49-60. 
10. Lamb E. Top 200 prescription drugs of 2006. Pharm Times. 2007; 73(5):34-37.

11. Kim TW, Islam T, Jung KY. Design and synthesis of non-steroidal diclofenac derivatives as anti-inflammatory drugs. J Ind Eng Chem. 2010;16(3):461-466.

12. Alam MA, Haque ME, Shilpi JA, Daulla KA. Antinociceptive effect of the crude ethanolic extract of crateva nurvala. Buch. on Mice. BJVM. 2006;4(1):65-68.

13. Cottrell J, O'Connor JP. Effect of non-steroidal anti-inflammatory drugs on bone healing. Pharmaceuticals. 2010;3(5):1668-1693.

14. Gan TJ. Diclofenac: an update on its mechanism of action and safety profile. Curr Med Res Opin. 2010;26(7):1715-1731.

15. Chiong HS, Somchit MN, Yaacob A, et al. Liposomal encapsulation of piroxicam: a strategy for improved anti-inflammatory and anti-pyretic activities. J Pharmacol Sci. 2011;115:275P-275P.

16. Goh JZ, Chiong HS, Zuraini A, et al. Rapid spectrophotometric determination, characterization and anti-inflammatory efficacy evaluation of nanoencapsulated diclofenac sodium. J Drug Del Sci Tech. 2014;24(4):361-366.

17. Parker AG, Peraza GG, Sena J, et al. Antinociceptive effects of the aqueous extract of Brugmansia suaveolens flowers in mice. Biol Res Nurs. 2007;8(3):234-239.

18. Zakaria ZA, Safarul M, Valsala R, et al. The influences of temperature and naloxone on the antinociceptive activity of Corchorus olitorius L. in mice. Naunyn-Schmiedeberg's Arch Pharmacol. 2005;372(1):55-62.

19. Bukhari IA, Khan RA, Gilani AH, Ahmed S, Saeed SA. Analgesic, anti-inflammatory and anti-platelet activities of the methanolic extract of Acacia modesta leaves. Inflammopharmacology. 2010;18(4):187-196.

20. Zakaria ZA, Raden Mohd Nor RNS, Hanan Kumar G, et al. Antinociceptive, anti-inflammatory and antipyretic properties of Melastoma malabathricum leaves aqueous extract in experimental animals. Can $J$ Physiol Pharmacol. 2006;84(12):1291-1299.

21. Woode E, Amoateng P, Ansah C, Duwiejua M. Anti-nociceptive effects of an ethanolic extract of the whole plant of Synedrella nodiflora (L.) Gaertn in mice: involvement of adrenosinergic mechanisms. $J$ Pharmacol Toxicol. 2009;4(1):17-29.

22. Zakaria ZA, Abdul Ghani ZDF, Raden Mohd Nor RNS, et al. Antinociceptive, anti-inflammatory, and antipyretic properties of an aqueous extract of Dicranopteris linearis leaves in experimental animal models. $J$ Nat Med. 2008;62(2):179-187.

23. Tao F, Tao YX, Zhao C, et al. Differential roles of neuronal and endothelial nitric oxide synthases during carrageenan-induced inflammatory hyperalgesia. Neuroscience. 2004;128:421-430.

24. George BP, Parimelazhagan T, Saravanan S, Chandran R. Antiinflammatory, analgesic and antipyretic properties of Rubus niveus Thunb. Root acetone extract. Pharmacologia. 2013;(4)3:228-235.
25. Ahmad KN, Kumar V, Raja S, Mukherjee K, Mukherjee PK. Antinociceptive and anti-inflammatory activity of Araucaria bidwillii hook. IJPT. 2005;4(2):105-109.

26. Le Bars D, Gozariu M, Cadden SW. Animal models of nociception. Pharmacol Rev. 2001;53(4):597-652.

27. Du J, Yu Y, Ke Y, Wang C, Zhu L, Qian ZM. Ligustilide attenuates pain behavior induced by acetic acid or formalin. J Ethnopharmacol. 2007;112:211-214.

28. Fezai M, Senovilla L, Jemaà M, Ben-Attia M. Analgesic, anti-inflammatory and anticancer activities of extra virgin olive oil. J Lipids. 2013;2013:129736.

29. Chiong HS, Hakim MN, Sulaiman MR, et al. Development and characterisation study of liposomes-encapsulated piroxicam. Int J Drug Deliv. 2011;3(1):64-73.

30. Al Ali SHH, Al-Qubaisi M, Hussein MZ, Zainal Z, Hakim MN. Preparation of hippurate-zinc layered hydroxide nanohybrid and its synergistic effect with tamoxifen on HepG2 cell lines. Int J Nanomedicine. 2011;6(1):3099-3111

31. Hasan S, Ali HA, Al-Qubaisi Mb, et al. Controlled-release formulation of antihistamine based on cetirizine zinc-layered hydroxide nanocomposites and its effect on histamine release from basophilic leukemia (RBL-2H3) cells. Int J Nanomedicine. 2012;7:3351-3363.

32. Hussein-Al-Ali SH, Al-Qubaisi M, Hussein MZ, Ismail M, Zainal Z, Hakim MN. In vitro inhibition of histamine release behavior of cetirizine intercalated into $\mathrm{Zn} / \mathrm{Al}$ - and $\mathrm{Mg} / \mathrm{Al}$-layered double hydroxides. Int $J$ Mol Sci. 2012;13(5):5899-5916.

33. Goh JZ, Tang SN, Zuraini A, et al. Enhanced anti-inflammatory effects of nanoencapsulated diclofenac. Eur J Inflamm. 2013;11(3):855-861.

34. O'connor N, Dargan PI, Jones AL. Hepatocellular damage from nonsteroidal anti-inflammatory drugs. QJM. 2003;96(11):787-791.

35. Dhikav V, Singh S, Pande S, Chawla A, Anand KS. Non-steroidal drug-induced gastrointestinal toxicity: mechanisms and management. J Indian Acad Clin Med. 2003;4(4):315-322.

36. Dhanvijay P, Misra AK, Varma SK. Diclofenac induced acute renal failure in a decompensated elderly patient. J Pharmacol Pharmacother. 2013;4(2):155-157.

37. Juárez-Rojop IE, Granados-Soto V, Díaz-Zagoya JC, FloresMurrieta FJ, Torres-López JE. Involvement of cholecystokinin in peripheral nociceptive sensitization during diabetes in rats as revealed by the formalin response. Pain. 2006;122(1-2):118-125.

38. Kidd BL, Urban LA. Mechanisms of inflammatory pain. Br J Anaesth 2001;87(1):3-11.
International Journal of Nanomedicine

\section{Publish your work in this journal}

The International Journal of Nanomedicine is an international, peerreviewed journal focusing on the application of nanotechnology in diagnostics, therapeutics, and drug delivery systems throughout the biomedical field. This journal is indexed on PubMed Central, MedLine, CAS, SciSearch ${ }^{\circledR}$, Current Contents ${ }^{\circledR} /$ Clinical Medicine,

\section{Dovepress}

Journal Citation Reports/Science Edition, EMBase, Scopus and the Elsevier Bibliographic databases. The manuscript management system is completely online and includes a very quick and fair peer-review system, which is all easy to use. Visit http://www.dovepress.com/ testimonials.php to read real quotes from published authors. 